\title{
Spotlight on frovatriptan: a review of its efficacy in the treatment of migraine
}

This article was published in the following Dove Press journal:

Drug Design, Development and Therapy

3 October 2016

Number of times this article has been viewed

\section{Gianni Allais \\ Chiara Benedetto}

Department of Surgical Sciences, Women's Headache Center, University of Turin, Turin, Italy

Video abstract

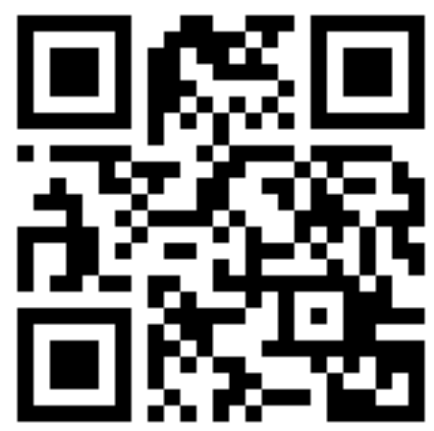

Point your SmartPhone at the code above. If you have a QR code reader the video abstract will appear. Or use: http://youtu.be/f7DnflfD5fs

Correspondence: Gianni Allais Department of Surgical Sciences, Women's Headache Center, University of Turin, Via Ventimiglia 3, 10I26 Turin, Italy

$\mathrm{Tel}+39$ I I 355023

Fax +39 II 355320

Email gb.allais@tiscali.it
Abstract: Migraine is a common neurovascular disorder, affecting millions of people worldwide. Current guidelines recommend triptans as first-line treatment for moderate-to-severe migraine attacks. Frovatriptan is a second-generation triptan with a longer terminal elimination half-life in blood than other triptans ( $\sim 26$ hours). Three double-blind, randomized crossover preference studies have been recently conducted, assessing efficacy and safety of frovatriptan versus rizatriptan, zolmitriptan, and almotriptan, respectively. Frovatriptan showed favorable tolerability and sustained effect, with a significantly lower rate of relapse over 48 hours versus the other triptans. These findings were confirmed in a series of analyses of patient subsets from the three studies, including patients with menstrually related and oral contraceptive-induced migraine, hypertension, obesity, weekend migraine, as well as patients with migraine with aura. In all patient subsets analyzed, lower headache recurrence rates were observed versus the comparator triptans, indicating a more sustained pain-relieving effect on migraine symptoms. A further randomized, double-blind study demonstrated that frovatriptan given in combination with the fast-acting cyclooxygenase inhibitor dexketoprofen provided improved migraine pain-free activity at 2 hours, and gave more sustained pain-free activity at 24 hours, versus frovatriptan alone. These benefits were observed both when the combination was administered early $(<1$ hour after symptom onset) or late ( $>1$ hour after onset). Different pharmacokinetic, but synergistic, properties between frovatriptan and dexketoprofen may make the combination of these agents particularly effective in migraine treatment, with rapid onset of action and sustained effect over 48 hours. These benefits, together with potential cost-effectiveness advantages versus other triptans could drive selection of the most appropriate treatment for acute migraine attacks.

Keywords: migraine, frovatriptan, menstrual, dexketoprofen, triptans, migraine with aura

\section{Introduction}

Migraine is a common neurovascular disorder, affecting millions of people worldwide. Migraine without aura is the most commonly experienced type of migraine, ${ }^{2}$ with this type of migraine often having a relationship with the menstrual cycle. ${ }^{2}$ Indeed, in $\sim 50 \%$ of females suffering from migraine, there is a menstrual association. ${ }^{3}$

Current guidelines advocate a stratified approach to migraine treatment, with the choice of initial treatment based on the severity of the attack. Migraine-specific drugs such as triptans are recommended as first-line therapy for moderate/severe attacks. ${ }^{4,5}$ Triptans form a group of selective serotonin 5HT-1 receptor agonists, and are widely considered to be the most effective acute treatment for migraine.${ }^{6,7}$ For mild/moderate attacks, nonsteroidal anti-inflammatory drugs (NSAIDs) and/or simple analgesics are recommended as initial treatment, ${ }^{4,5}$ with triptans indicated if response to such nonspecific drugs is considered inadequate. A treatment algorithm for migraine has recently been created ${ }^{8}$ (Figure 1). 


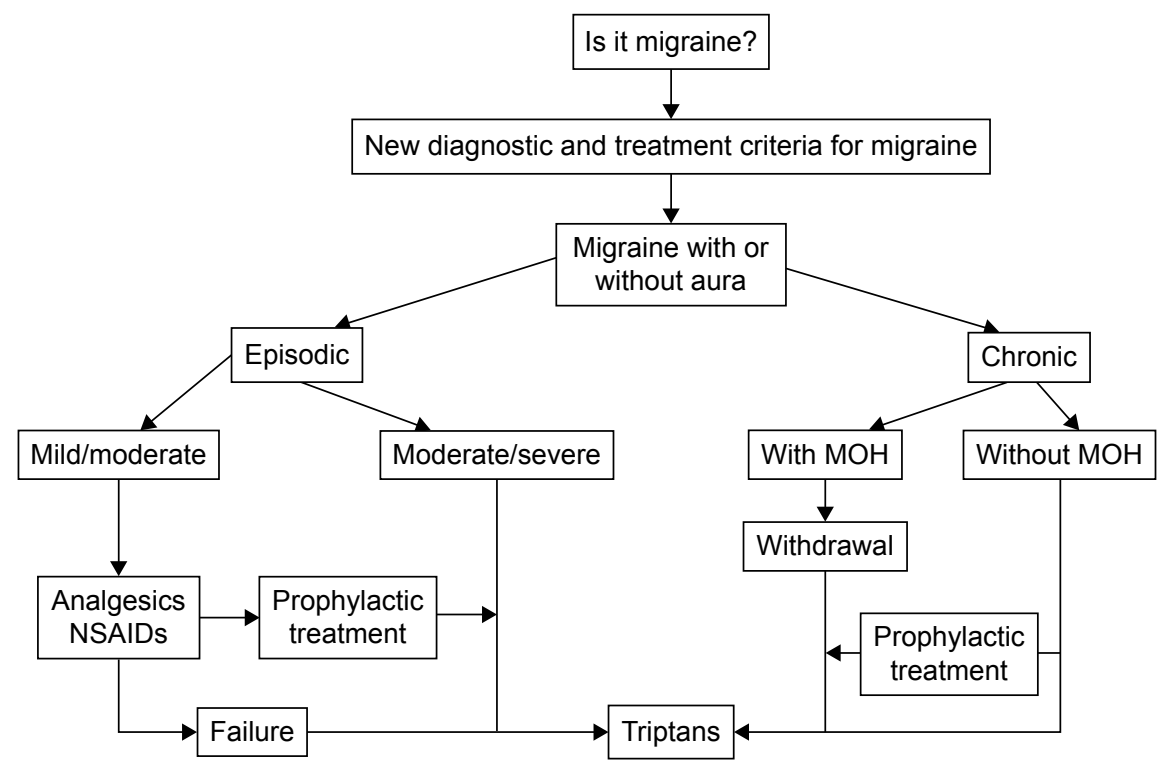

Figure I Treatment algorithm for migraine.

Note: Republished from Touch Medical Media from An algorithm of migraine treatment, Evers S, Lisotto C. Eur Neurol Rev. 20I3;8(2); permission conveyed through Copyright Clearance Center, Inc.

Abbreviations: $\mathrm{MOH}$, medication-overuse headache; NSAIDs, nonsteroidal anti-inflammatory drugs.

The first triptan to be discovered was sumatriptan, following which a number of second-generation triptans were developed. Frovatriptan is one of these second-generation triptans (Table 1); it has a longer terminal elimination halflife in blood compared with other triptans ( 26 hours $),{ }^{9}$ and was specifically developed to provide a long duration of action and a low likelihood of side effects. ${ }^{10}$ Randomized clinical studies and postmarketing surveys have demonstrated significantly improved effectiveness and tolerability with frovatriptan compared with previous acute therapies, including other triptans. ${ }^{11,12}$
Three direct comparative, double-blind, randomized, crossover studies have assessed the efficacy and safety of frovatriptan $(2.5 \mathrm{mg})$ and compared it with that of rizatriptan $(10 \mathrm{mg}),{ }^{13}$ zolmitriptan $(2.5 \mathrm{mg}),{ }^{14}$ and almotriptan $(12.5 \mathrm{mg}) .{ }^{15}$ Recently, post hoc analyses of these three studies have compared the efficacy of frovatriptan versus rizatriptan, zolmitriptan, and almotriptan in a number of specific patient subsets, including patients with menstrually related migraine, ${ }^{16-19}$ oral contraceptive-induced migraine, ${ }^{20}$ hypertension, ${ }^{21}$ obesity, ${ }^{22}$ weekend migraine,,${ }^{23}$ as well as in patients with migraine with aura..$^{24,25}$

Table I Overview of frovatriptan for the treatment of migraine

\begin{tabular}{|c|c|c|c|c|}
\hline $\begin{array}{l}\text { Pharmacologic } \\
\text { characteristics }\end{array}$ & Efficacy & Safety & $\begin{array}{l}\text { Patient } \\
\text { preference }\end{array}$ & Cost-effectiveness \\
\hline $\begin{array}{l}\text { High affinity for } 5-\mathrm{HT}(\mathrm{IB} / \mathrm{ID}) \\
\text { receptors } \\
60 \%-70 \% \text { of plasma maximum } \\
\text { concentration achieved within } \\
\text { I hour of dosing } \\
\text { Time to maximum } \\
\text { concentration } 2-3 \text { hours } \\
\text { Longer half-life than other } \\
\text { triptans ( } 26 \text { hours) } \\
\text { Elimination route and } \\
\text { metabolism: hepatic } \\
\text { metabolism via CYPIA2 } \\
\text { isoenzyme of cytochrome } \\
\text { P450; renal clearance accounts } \\
\text { for } 40 \% \text { of total clearance } \\
\text { Recommended dose: } 2.5 \text { mg } \\
\text { (tablets) } \\
\text { Maximum daily dose: } 5 \text { mg }\end{array}$ & $\begin{array}{l}\text { Similar immediate efficacy } \\
\text { to comparators (rizatriptan, } \\
\text { zolmitriptan, and almotriptan) }{ }^{30} \\
\text { Greater sustained antimigraine } \\
\text { effect versus comparators }{ }^{30} \\
\text { Effective in menstrually } \\
\text { related migraine with lower } \\
\text { risk of recurrence versus } \\
\text { comparators }{ }^{19} \\
\text { When given with } \\
\text { dexketoprofen, the } \\
\text { combination is similarly } \\
\text { effective regardless of early } \\
\text { ( }<\text { I hour) or late ( }>\text { I hour) } \\
\text { administration }{ }^{27} \\
\text { Effective in both migraine with } \\
\text { and without aura (when taken } \\
\text { in the headache phase) }{ }^{24}\end{array}$ & $\begin{array}{l}\text { Generally well tolerated }{ }^{30} \\
\text { Most common AEs } \\
\text { (dizziness, fatigue, } \\
\text { paresthesia, headache, } \\
\text { and vascular flushing) } \\
\text { are transient, generally } \\
\text { of mild-to-moderate } \\
\text { intensity, and resolve } \\
\text { spontaneously } \\
\text { Favorable safety profile } \\
\text { compared to other }_{\text {triptans }^{30}}\end{array}$ & $\begin{array}{l}\text { Similar patient } \\
\text { preference } \\
\text { results versus } \\
\text { other triptans }^{13-15}\end{array}$ & $\begin{array}{l}\text { Model analysis suggests } \\
\text { economical advantage } \\
\text { versus other triptans }{ }^{49} \\
\text { Lower acquisition } \\
\text { cost, need for fewer } \\
\text { doses, and loss of fewer } \\
\text { working hours versus } \\
\text { other triptans }{ }^{49} \\
\text { Significantly more } \\
\text { cost-effective than } \\
\text { rizatriptan }{ }^{49}\end{array}$ \\
\hline
\end{tabular}

Abbreviation: AEs, adverse events. 
The efficacy of the combination of frovatriptan and the NSAID dexketoprofen has also recently been investigated. ${ }^{26-28}$

This review aims to provide an overview of the efficacy of frovatriptan in the acute treatment of migraine, in light of recent publications.

\section{Frovatriptan in the acute treatment of migraine: evidence from randomized controlled studies}

The three direct comparative, double-blind, randomized, crossover studies involved 33 centers across Italy, and shared a similar study design. The studies included patients from both sexes, aged 18-65 years, with a current history of migraine with or without aura, according to International Headache Society 2004 criteria $^{29}$ and with between one and six migraine attacks per month for 6 months before commencing the study. Frovatriptan $2.5 \mathrm{mg}$ was compared with rizatriptan $10 \mathrm{mg}$ in the first study, zolmitriptan $2.5 \mathrm{mg}$ in the second study, and almotriptan $12.5 \mathrm{mg}$ in the third study. After treating three episodes of migraine in not $>3$ months with the first treatment, the patient switched to the other treatment. Patients were encouraged to treat one to three attacks for a maximum period of 6 months. Patients with no migraine episodes during one of the two observation periods were excluded. The primary end point of the studies was the between-treatment comparison of the direction and strength of patient preference, assessed by a questionnaire at the end of the study, and measured on a scale from 0 (no preference) to 5 (strong preference). Secondary end points included numbers of pain-free at 2 hours, pain relief at 2 hours, pain-free at 24 hours, and recurrence of headache within 48 hours. End points for each of the studies are summarized in Table 2.

Average preference scores did not differ significantly between the triptans in the three studies (Table 2). In each individual study, similar efficacy was demonstrated between the four triptans in the immediate treatment of migraine, but there were lower recurrence rates, and thus a better sustained pain relief with frovatriptan (Table 2). A pooled analysis of the three studies was subsequently conducted. ${ }^{30}$ Rates of pain-free and pain-relief episodes at 2 hours, and sustained pain-free episodes at 48 hours, were similar between frovatriptan and comparators. ${ }^{30}$ However, consistent with the results of the individual studies, frovatriptan demonstrated significantly lower headache recurrence rates over 48 hours $(27 \%$ versus $40 \%$ with comparators; $P<0.001$ ) (Figure 2). ${ }^{30}$ The lower recurrence rate with frovatriptan may be explained by its longer elimination half-life versus rizatriptan, zolmitriptan, and almotriptan (25-26 versus $2-4$ hours). ${ }^{31}$

\section{Frovatriptan in the acute treatment of menstrual migraine}

Menstrual migraine attacks are more severe, have a longer duration, and respond less well to analgesics compared to nonmenstrual attacks. ${ }^{32}$ The development of diagnostic criteria $^{2}$ has led to increased recognition of menstrual migraine as a frequently occurring and disabling condition warranting specific treatment. Two clinical forms of menstrual migraine exist: pure menstrual migraine and menstrually related migraine.

\section{Pure menstrual migraine}

In pure menstrual migraine, the attacks occur exclusively on day $1 \pm 2$ (ie, days -2 to +3 ) of menstruation in at least two out of three menstrual cycles and at no other times of the cycle. ${ }^{2}$

\section{Menstrually related migraine}

In menstrually related migraine, attacks occur on day $1 \pm 2$ (ie, days -2 to +3 ) of menstruation in at least two out of three menstrual cycles and additionally at other times of the cycle. ${ }^{2}$

Prespecified subgroup analyses of the three randomized, crossover studies were carried out in females with menstrually related migraine, ${ }^{16-18}$ and a pooled analysis was then carried out on these three subanalysis studies. ${ }^{19}$ Similar proportions of pain-relief and pain-free episodes were observed at 2, 4, and 24 hours. However, once again, frovatriptan demonstrated lower headache recurrence rates over 24 hours and even more so over 48 hours (Table 2) ${ }^{19}$ Figure 3 shows the greatly reduced risk of recurrence demonstrated with frovatriptan versus other triptans.

\section{Oral contraceptive-induced menstrual migraine} Oral contraceptive-induced menstrual migraine is primarily triggered by estrogen withdrawal during the week of pill suspension, ${ }^{2}$ although this migraine subtype has not been widely studied. An additional post hoc analysis of the three crossover studies ${ }^{13-15}$ found that frovatriptan had similar efficacy to comparators in the immediate treatment of acute attacks of oral contraceptive-induced menstrual migraine. ${ }^{20}$ However, relapse at 24 and 48 hours was significantly lower with frovatriptan than with the comparators (Table 2), potentially making frovatriptan more suitable for treatment of this form of migraine.

Some form of preventive drug treatment may be useful for menstrual migraine.$^{33}$ However, acute treatment is typically 
Table 2 Summary of key studies and subanalyses evaluating the efficacy and safety of frovatriptan versus rizatriptan, zolmitriptan, and almotriptan

\begin{tabular}{ll}
\hline Study & Primary end points \\
\hline Key studies & \\
Frovatriptan & Average preference score: $2.9 \pm 1.3$ for frovatriptan; \\
versus & $3.2 \pm 1.1$ for rizatriptan $(P=N S)$ \\
rizatriptan &
\end{tabular}

Frovatriptan

versus zolmitriptan ${ }^{14}$

Frovatriptan

versus almotriptan $^{15}$

Subanalyses Frovatriptan versus rizatriptan in menstrual migraine $^{16}$

\section{Frovatriptan versus zolmitriptan in menstrual migraine $^{17}$}

Pain relief at 2 hours: No significant difference between treatments

Pain relief at 24 hours: No significant difference between treatments

Pain-free at 2 hours: No significant difference between treatments

Pain-free at 24 hours: No significant difference between treatments

Recurrence within 24 hours: $10 \%$ versus $32 \%$ for frovatriptan and rizatriptan, respectively; $P<0.01$

Pain relief at 2 hours: No significant difference between treatments

Pain relief at 24 hours: No significant difference between treatments

Pain-free at 2 hours: No significant difference between treatments

Pain-free at 24 hours: No significant difference between treatments

Recurrence within 24 hours: $15 \%$ versus $22 \%$ for frovatriptan and zolmitriptan, respectively; $P<0.05$

\section{Key secondary end points}

Pain-free at 2 hours: No significant difference between treatments

Recurrence within 48 hours according to protocol: $22 \%$ versus $32 \%$ for frovatriptan and rizatriptan, respectively; $P<0.00$ I

Recurrence within 48 hours according to IHS criteria: $21 \%$ versus $43 \%$ for frovatriptan and rizatriptan, respectively; $P<0.001$

Sustained pain-free at 48 hours: No significant difference between treatments

Pain relief at 2 hours: No significant difference between treatments

Pain-free at 2 hours: No significant difference between treatments

Rate of recurrence within 48 hours: No significant difference between treatments

Time to recurrence within 48 hours: Significantly better for frovatriptan, especially between 4 and 16 hours $(P<0.05)$ Sustained pain-free at 48 hours: No significant difference between treatments

Pain relief at 2 hours: No significant difference between treatments

Pain-free at 2 hours: No significant difference between treatments

Recurrence within 48 hours according to protocol: $28 \%$ versus $34 \%$ for frovatriptan and almotriptan, respectively; $P<0.05$ Recurrence within 48 hours according to IHS criteria: $30 \%$ versus $44 \%$ for frovatriptan and almotriptan, respectively; $P<0.05$

Sustained pain-free at 48 hours: No significant difference between treatments

Pain relief at 2 hours: No significant difference between treatments

Pain relief and pain-free after frovatriptan intake for MRM and non-MRM

Pain relief at 2 hours: No significant difference between MRM and non-MRM

Pain relief at 24 hours: No significant difference between MRM and non-MRM

Pain-free at 2 hours: No significant difference between MRM and non-MRM

Pain-free at 24 hours: No significant difference between MRM and non-MRM

Migraine intensity: Significantly larger reduction with frovatriptan than with rizatriptan at 24 and 48 hours

$(P<0.0$ I $)$

Pain relief and pain-free after frovatriptan intake for MRM and non-MRM

Pain relief at 2 hours: No significant difference between MRM and non-MRM

Pain relief at 24 hours: No significant difference between MRM and non-MRM

Pain-free at 2 hours: No significant difference between MRM and non-MRM

Pain-free at 24 hours: No significant difference between MRM and non-MRM 
Table 2 (Continued)

\begin{tabular}{|c|c|c|}
\hline Study & Primary end points & Key secondary end points \\
\hline $\begin{array}{l}\text { Frovatriptan } \\
\text { versus } \\
\text { almotriptan } \\
\text { in menstrual } \\
\text { migraine }^{18}\end{array}$ & $\begin{array}{l}\text { Pain relief at } 2 \text { hours: No significant difference between } \\
\text { treatments } \\
\text { Pain relief at } 4 \text { hours: No significant difference between } \\
\text { treatments } \\
\text { Pain relief at } 24 \text { hours: No significant difference between } \\
\text { treatments } \\
\text { Pain-free at } 2 \text { hours: No significant difference between treatments } \\
\text { Pain-free at } 4 \text { hours: No significant difference between treatments } \\
\text { Pain-free at } 24 \text { hours: No significant difference between } \\
\text { treatments } \\
\text { Recurrence within } 24 \text { hours: } 8 \% \text { versus } 21 \% \text { for frovatriptan } \\
\text { and rizatriptan, respectively; } P<0.05 \\
\text { Recurrence within } 48 \text { hours: } 9 \% \text { versus } 24 \% \text { for frovatriptan } \\
\text { and rizatriptan, respectively; } P<0.05\end{array}$ & $\begin{array}{l}\text { Migraine intensity: Significantly larger reduction with } \\
\text { frovatriptan than with almotriptan at } 24 \text { and } 48 \text { hours }(P<0.05)\end{array}$ \\
\hline $\begin{array}{l}\text { Frovatriptan } \\
\text { versus } \\
\text { comparators } \\
\text { in menstrual } \\
\text { migraine: Pooled } \\
\text { analysis }^{19}\end{array}$ & $\begin{array}{l}\text { Pain relief at } 2 \text { hours: No significant difference between } \\
\text { frovatriptan versus comparators } \\
\text { Pain relief at } 4 \text { hours: No significant difference between } \\
\text { frovatriptan versus comparators } \\
\text { Pain relief at } 24 \text { hours: No significant difference between } \\
\text { frovatriptan versus comparators } \\
\text { Pain-free at } 2 \text { hours: No significant difference between } \\
\text { frovatriptan versus comparators } \\
\text { Pain-free at } 4 \text { hours: No significant difference between } \\
\text { frovatriptan versus comparators } \\
\text { Pain-free at } 24 \text { hours: No significant difference between } \\
\text { frovatriptan versus comparators } \\
\text { Recurrence within } 24 \text { hours: I } \% \text { versus } 24 \% \text { for frovatriptan } \\
\text { and comparators, respectively; } P<0.05 \\
\text { Recurrence within } 48 \text { hours: I } 5 \% \text { versus } 26 \% \text { for frovatriptan } \\
\text { and comparators, respectively; } P<0.05\end{array}$ & $\mathrm{~N} / \mathrm{A}$ \\
\hline $\begin{array}{l}\text { Frovatriptan } \\
\text { versus } \\
\text { comparators } \\
\text { in oral } \\
\text { contraceptive- } \\
\text { induced } \\
\text { migraine: Pooled } \\
\text { analysis }{ }^{20}\end{array}$ & $\begin{array}{l}\text { Pain relief at } 2 \text { hours: No significant difference between } \\
\text { frovatriptan versus comparators } \\
\text { Pain relief at } 24 \text { hours: Frovatriptan versus comparators } \\
\text { Pain-free at } 2 \text { hours: No significant difference between } \\
\text { frovatriptan versus comparators } \\
\text { Pain-free at } 24 \text { hours: } 71 \% \text { versus } 60 \% \text { for frovatriptan and } \\
\text { comparators, respectively; } P<0.05 \\
\text { Recurrence within } 24 \text { hours: } 17 \% \text { versus } 27 \% \text { for frovatriptan } \\
\text { and comparators, respectively; } P<0.05 \\
\text { Recurrence within } 48 \text { hours: } 21 \% \text { versus } 31 \% \text { for frovatriptan } \\
\text { and comparators, respectively; } P<0.05\end{array}$ & $\mathrm{~N} / \mathrm{A}$ \\
\hline $\begin{array}{l}\text { Fovatriptan } \\
\text { versus } \\
\text { comparators in } \\
\text { hypertensive and } \\
\text { normotensive } \\
\text { subjects }^{21}\end{array}$ & $\begin{array}{l}\text { Pain relief at } 2 \text { hours: Significantly lower for hypertensive } \\
\text { versus normotensive subjects for either frovatriptan or } \\
\text { comparators ( } 41 \% \text { versus } 52 \% \text { for frovatriptan; } P<0.05 \text { and } \\
48 \% \text { versus } 58 \% \text { for comparators; } P<0.05 \text { ) } \\
\text { Pain-free at } 2 \text { hours: No significant difference between } \\
\text { hypertensive and normontensive subjects for either } \\
\text { frovatriptan or comparators } \\
\text { Recurrence within } 48 \text { hours: No significant difference between } \\
\text { hypertensive and normotensive subjects for frovatriptan; } \\
\text { significantly larger in hypertensive versus normotensive } \\
\text { subjects for comparators }(62 \% \text { versus } 44 \% ; P<0.05)\end{array}$ & $\mathrm{N} / \mathrm{A}$ \\
\hline $\begin{array}{l}\text { Frovatriptan } \\
\text { versus } \\
\text { comparators } \\
\text { in obese and } \\
\text { normal-weight } \\
\text { subjects }^{22}\end{array}$ & $\begin{array}{l}\text { Pain relief at } 2 \text { hours: No significant difference between } \\
\text { frovatriptan versus comparators in either nonobese or obese } \\
\text { subjects } \\
\text { Pain-free at } 2 \text { hours: No significant difference between } \\
\text { frovatriptan versus comparators in either nonobese or obese } \\
\text { subjects. Significantly greater in nonobese versus obese subjects }\end{array}$ & N/A \\
\hline
\end{tabular}


Table 2 (Continued)

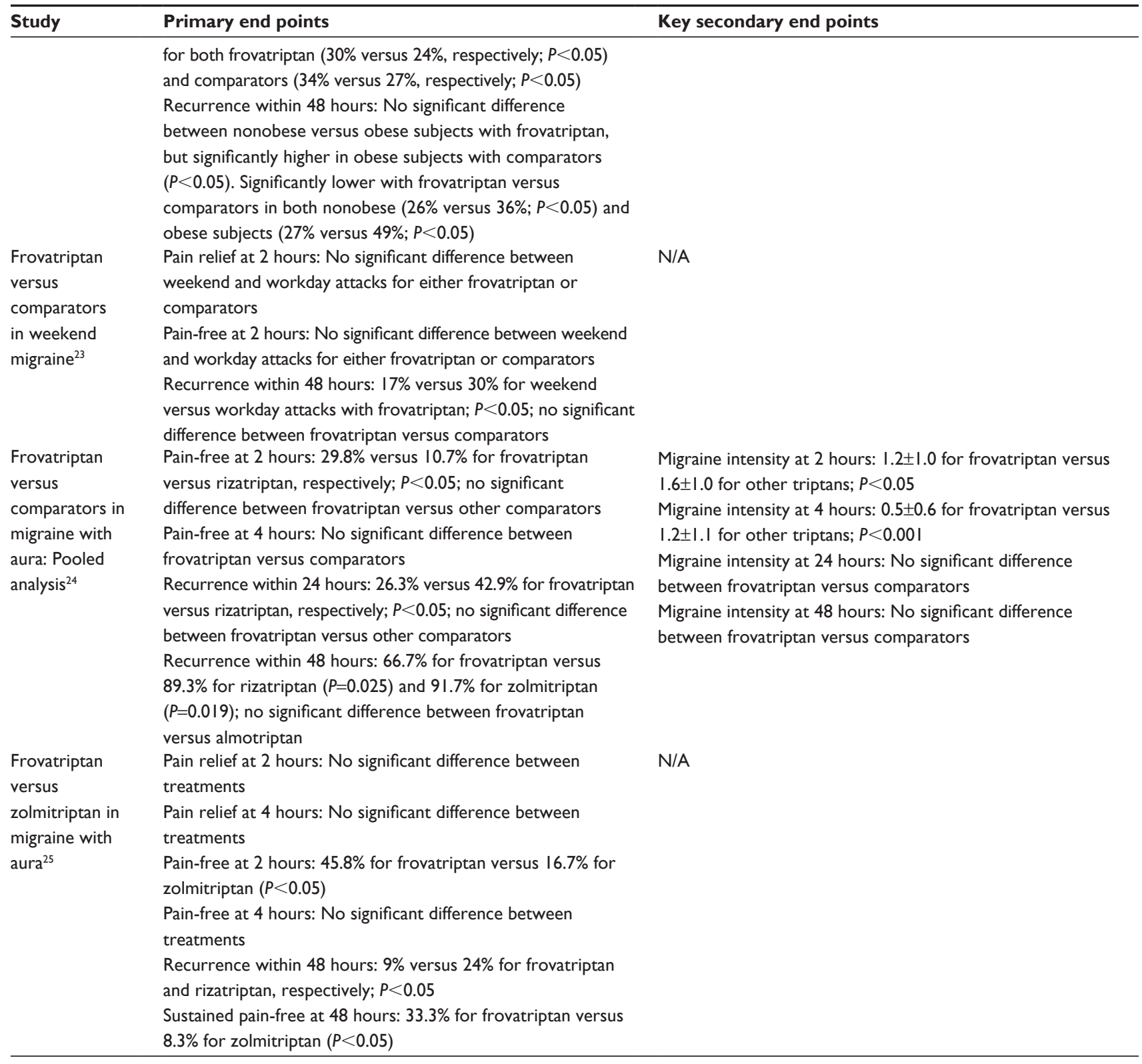

Abbreviations: IHS, International Headache Society; MRM, menstrually related migraine attacks; N/A, not applicable; NS, not significant.

more effective, ${ }^{34}$ and helps to avoid medication overuse. While the frovatriptan summary of product characteristics states that it should not be used prophylactically, ${ }^{35}$ there is level A evidence indicating that frovatriptan is effective for prevention of menstrual migraine, ${ }^{36}$ making it the only triptan efficacious for both acute and prophylactic migraine treatment.

\section{Frovatriptan in combination with dexketoprofen for both early and late treatment administration}

NSAIDs are indicated in the symptomatic treatment of migraine, particularly for episodic mild/moderate attacks ${ }^{5}$
(Figure 1). The cyclooxygenase inhibitor dexketoprofen reaches maximal plasma concentration after 30 minutes and has been shown to provide rapid reduction of pain in patients with migraine with or without aura. ${ }^{37,38}$

The combination of frovatriptan and dexketoprofen was investigated in a recent randomized, double-blind, parallel group study. ${ }^{28}$ The rationale for combining these two agents is linked to the different intrinsic pharmacokinetic properties of each drug, and the potential to target different mechanisms involved in migraine. The primary end point was the proportion pain-free at 2 hours. Secondary end points included pain-free and pain relief at 1,2, and 4 hours, 
A

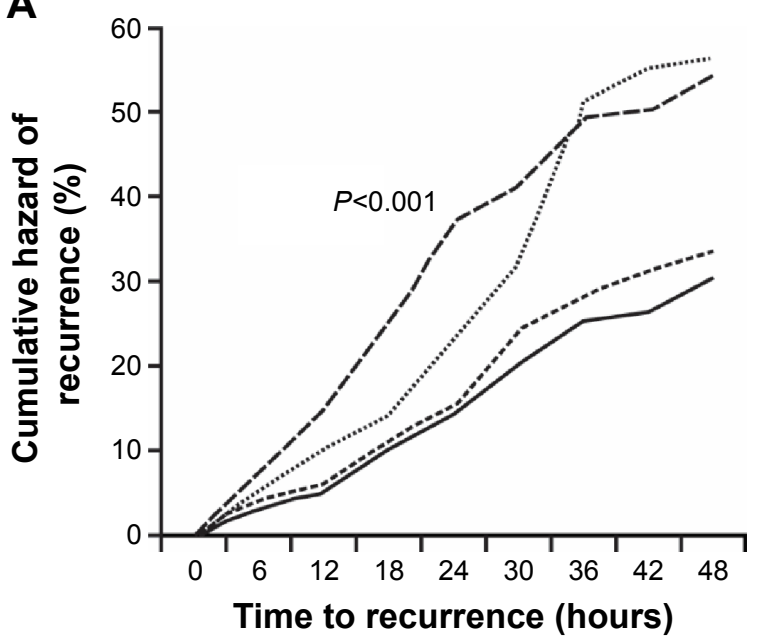

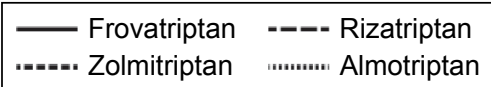

B

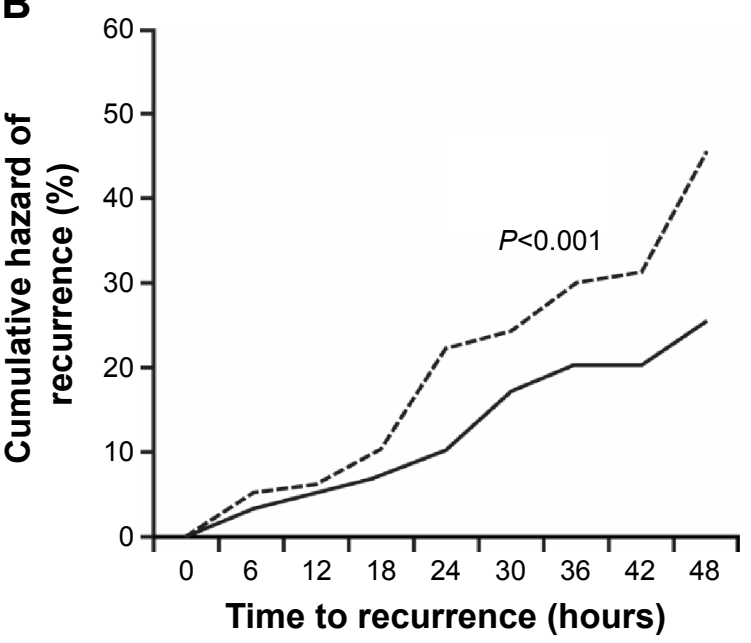

Frovatriptan ----- Comparator

Figure 2 Cumulative hazard of recurrence over 48 hours during treatment with frovatriptan or comparators $(n=346)$.

Notes: Data are shown separately for each comparator (A) or by pooling together data from the three comparators (B). Reproduced from Neurol Sci. Frovatriptan versus other triptans in the acute treatment of migraine: pooled analysis of three double-blind, randomized, cross-over, multicenter, Italian studies. Volume 32(Suppl I), 20I I, pages S95-S98. Cortelli P, Allais G, Tullo V, et al. With permission of Springer. ${ }^{30}$

sustained pain-free at 24 and 48 hours, and recurrence at 48 hours. The study demonstrated that the combination of frovatriptan $2.5 \mathrm{mg}$ and dexketoprofen ( 25 or $37.5 \mathrm{mg}$ ) provided migraine pain-free activity at 2 hours in $51 \%$ of patients (versus $29 \%$ with frovatriptan alone; $P<0.05$ [primary end point]). Pain relief at 2 hours was $\sim 80 \%$ with both combinations, while sustained pain-free activity at 24 and 48 hours

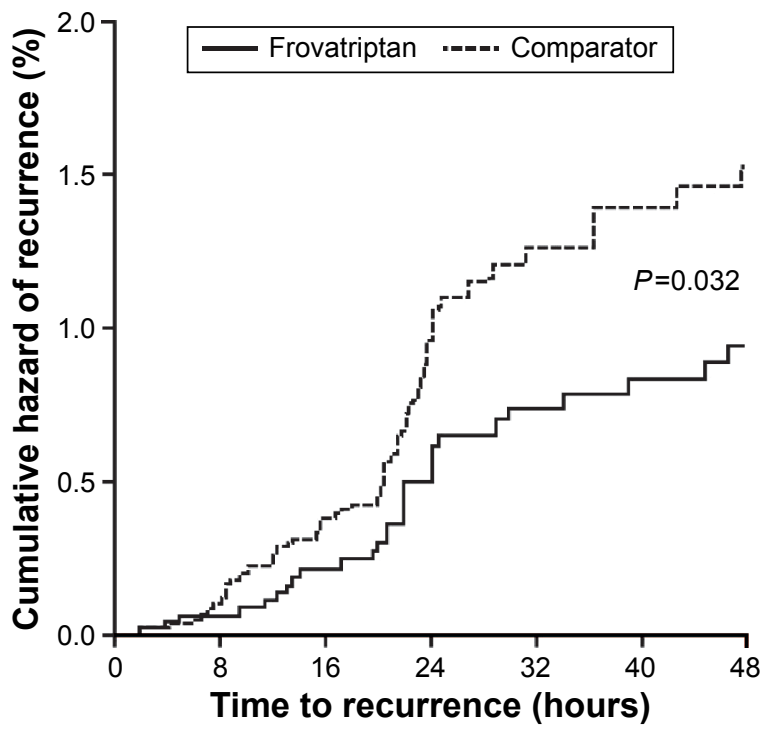

Figure 3 Cumulative hazard of recurrence over 48 hours in females with menstrual migraine during treatment with frovatriptan versus comparators.

Note: Reproduced from Allais G, Tullo V, Omboni S, et al. Efficacy of frovatriptan versus other triptans in the acute treatment of menstrual migraine: pooled analysis of three double-blind, randomized, crossover, multicenter studies. Neurol Sci. 20I2; 33(Suppl I):S65-S69. ${ }^{19}$ was achieved with frovatriptan plus dexketoprofen $25 \mathrm{mg}$ in $43 \%$ and $36 \%$ of patients, respectively (secondary end points). ${ }^{28}$ This final end point is of particular importance, as it is often considered the more difficult factor to treat.

In contrast to treatment with triptan monotherapy, where early timing of administration plays a key role in providing pain relief, the timing of combination treatment relative to headache onset did not appear to influence clinical benefits of the drug combination. ${ }^{26}$

A further post hoc analysis of the study specifically evaluated the efficacy of frovatriptan plus dexketoprofen compared with monotherapy, when administered early $(<1$ hour after symptom onset) or late ( $>1$ hour after onset). ${ }^{27}$ Both early and late intake of the combination significantly improved pain-free and pain relief at 2 and 4 hours (Figure 4), with the combination therapy similarly efficacious in treating acute migraine attack irrespective of the time of drug intake. ${ }^{27}$ Furthermore, late intake of frovatriptan plus high-dose dexketoprofen proved efficient at managing the most severe and difficult attacks, decreasing the use of rescue medication, with $95 \%$ pain relief at 2 hours and $100 \%$ at 4 hours. This is noteworthy, as it lends support to the notion that the combination of triptan plus NSAIDs could potentially reduce the hazards of medication-overuse headaches and related adverse effects. ${ }^{39}$

These results suggest that the differences in pharmacokinetic properties between frovatriptan and dexketoprofen may 
Pain-free at 2 hours

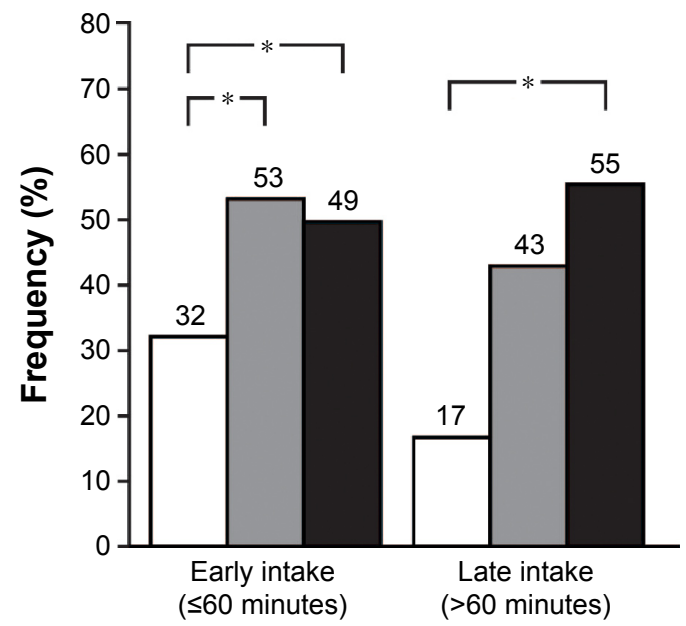

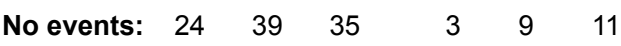

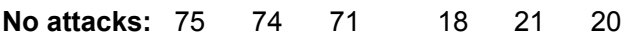

\section{Pain relief at 2 hours}

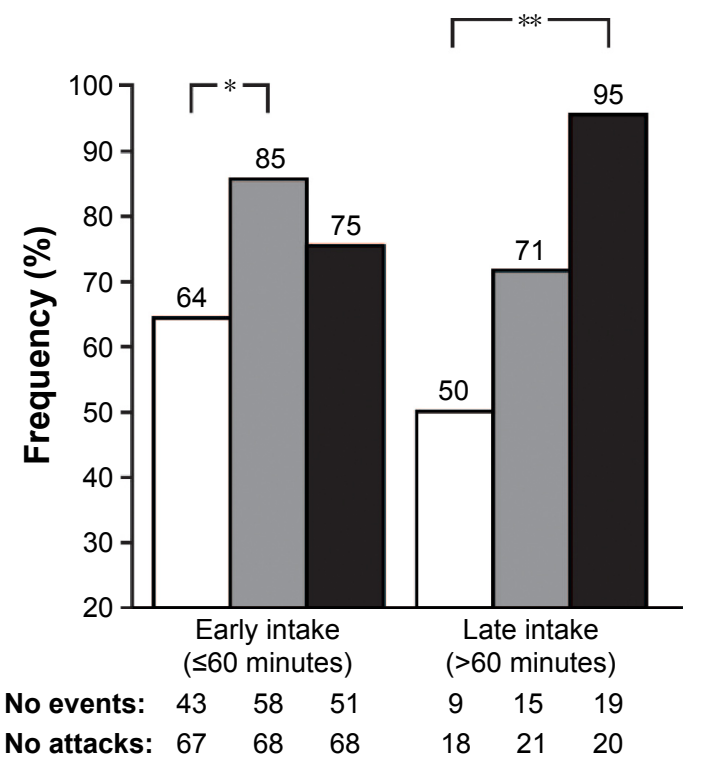

Pain-free at 4 hours

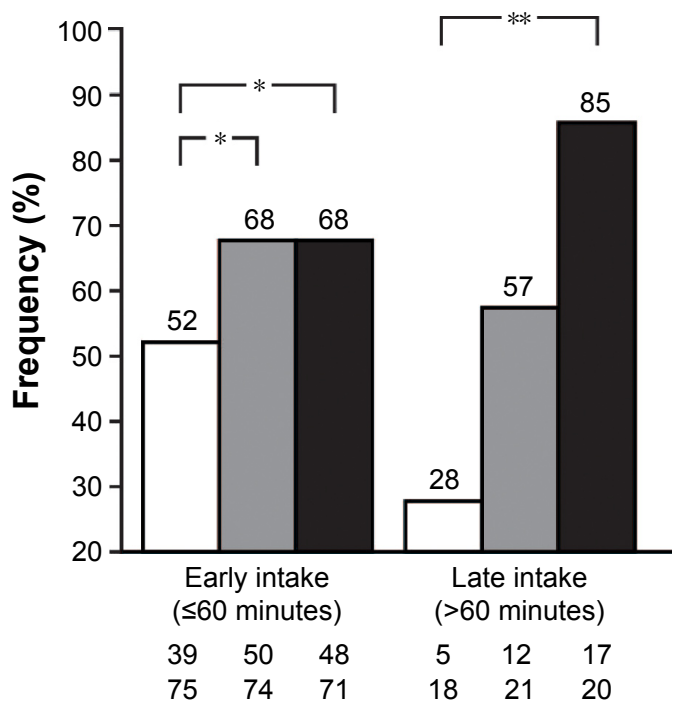

Pain relief at 4 hours

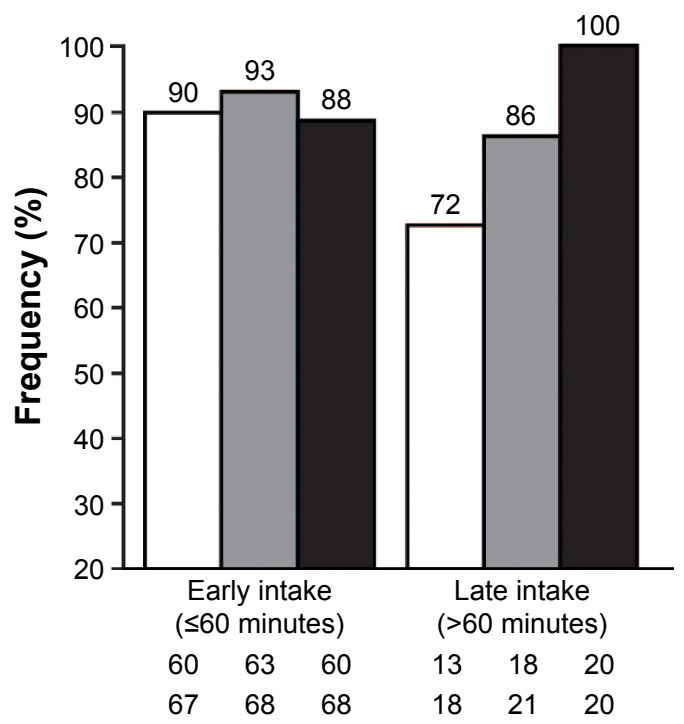

Figure 4 Proportion (\%) of pain-free at 2 and 4 hours, and of pain relief at 2 and 4 hours, after administration of frovatriptan 2.5 mg, frovatriptan 2.5 mg plus dexketoprofen $25 \mathrm{mg}$, and frovatriptan $2.5 \mathrm{mg}$ plus dexketoprofen $37.5 \mathrm{mg}$, by early and late drug intake.

Notes: White bars: frovatriptan $2.5 \mathrm{mg}$ monotherapy. Gray bars: frovatriptan $2.5 \mathrm{mg}$ plus dexketoprofen $25 \mathrm{mg}$. Black bars: frovatriptan $2.5 \mathrm{mg}$ plus dexketoprofen $37.5 \mathrm{mg}$. $* P<0.05$ and between the combination treatment and the monotherapy; $* * P<0.0$ l between the combination treatment and the monotherapy. Reproduced from Neurol Sci. Early $(\leq \mathrm{l}$ h) vs late $(>\mathrm{I} \mathrm{h})$ administration of frovatriptan plus dexketoprofen combination vs frovatriptan monotherapy in the acute treatment of migraine attacks with or without aura: a post hoc analysis of a double-blind, randomized, parallel group study. Volume 36 (Suppl I), 20I5, pages I6I-167. Allais G, Bussone G, Tullo V, et al. With permission of Springer. ${ }^{27}$

make the combination of these two agents particularly effective in migraine treatment, with dexketoprofen providing early pain relief while the longer half-life of frovatriptan reduces the risk of recurrence within 48 hours. ${ }^{27}$

\section{Frovatriptan for the treatment of migraine with aura}

Migraine with aura constitutes approximately 20\%-30\% of total migraine attacks, ${ }^{40}$ and can be difficult to treat. ${ }^{24}$ However, many patients suffer from both forms of attack. ${ }^{24}$
Evers et $\mathrm{a}^{24}$ performed a meta-analysis of the three previously described randomized, crossover trials, ${ }^{13-15}$ together with two other European studies with rizatriptan and zolmitriptan of similar trial design to the three previous studies (data on file).

Pain-free at 2 hours was significantly better with frovatriptan versus rizatriptan (Table 2) ${ }^{24}$ While higher pain-free rates at 2 hours were achieved with frovatriptan versus zolmitriptan and almotriptan, these did not reach statistical significance. In concordance with the results obtained in 
the analysis of all migraine attacks studied in the larger trial program, ${ }^{30}$ frovatriptan resulted in considerably lower relapse rate versus the comparators. ${ }^{24}$ These results are particularly important as there are few data published regarding triptan efficacy during the aura phase.

On a scale where the headache intensity was graded as $0=$ none $; 1=$ mild $; 2=$ moderate $3=$ severe, the mean headache intensity was lower with frovatriptan than with the other triptans at both 2 and 4 hours (secondary end points; Table 2). The authors speculate that the severe and long-lasting attacks experienced by patients enrolled, as confirmed by baseline characteristics and migraine disability assessment scores, may have contributed to the particular efficacy demonstrated by frovatriptan at the 2- and 4-hour timepoints. ${ }^{24}$ It should be noted that, while patients were advised to take the study drug at the start of the headache phase, and not during aura, it is possible that, in some patients, the aura phase was still ongoing at the time of drug intake.

A post hoc analysis of the original randomized, double-blind, crossover study ${ }^{14}$ was carried out in patients with a diagnosis of migraine with aura, independently of whether the study drug was taken during aura or headache phase. ${ }^{25}$ The analysis showed the proportion of pain-free episodes at 2 hours to be significantly greater with frovatriptan (Table 2). Sustained pain-free episodes over 48 hours were also reported significantly more frequently with frovatriptan versus zolmitriptan (Table 2).

Triptans are not approved to be taken during the aura phase of migraine with aura, ${ }^{24}$ due to a current lack of data in this setting.

\section{Frovatriptan benefits in migraine: evidence from additional subanalyses of the three randomized, controlled studies Hypertension}

Hypertension may be associated with migraine, with high blood pressure potentially enhancing the effects of migraine on the vascular wall, leading to further impairment of cerebral endothelial function, resulting in a form of migraine that may be more difficult to treat. ${ }^{21,41}$ Tullo et $\mathrm{al}^{21}$ assessed triptan efficacy in subjects with a history of treated or untreated essential arterial hypertension versus normotensive subjects. Pain relief was achieved on significantly fewer occasions in hypertensive than normotensive subjects for frovatriptan and the comparators (Table 2). However, frovatriptan displayed a more sustained antimigraine effect in both hypertensive and normotensive subjects, with relapses at 48 hours similarly low in hypertensive and normotensive subjects following frovatriptan treatment, and significantly larger relapse rates in hypertensive and normotensive subjects with comparators (Table 2).

\section{Obesity}

There have been observations of an association between migraine and obesity, which are supported by potential biological mechanisms. ${ }^{42}$ While adult weight-based dose adjustment is not currently recommended in the product information for the available triptans, the need for increased doses in obese patients remains unclear, ${ }^{43}$ with anecdotal evidence suggesting that obese migraineurs may take higher numbers of tablets of their antimigraine medication due to their condition.

Saracco et $\mathrm{al}^{22}$ compared efficacy and safety of frovatriptan against the three comparators in nonobese versus overweight and obese subjects. The proportion pain-free at 2 hours did not significantly differ between frovatriptan and the comparators in either nonobese or obese subjects. However, the proportion pain-free at 2 hours was significantly larger in nonobese than in obese subjects irrespective of the type of triptan. Recurrence at 48 hours occurred in significantly fewer episodes treated with frovatriptan versus comparators in both nonobese and obese subjects (Table 2).

Of note, the rate of relapse in 48 hours was similar in nonobese and obese subjects with frovatriptan, while it was significantly higher in obese subjects with the comparators. These results suggest that the long half-life of frovatriptan may ensure a low rate of headache recurrence in obese as well as normal-weight individuals, which may be important given that obesity is common among individuals with migraine. ${ }^{22}$ The results confirm that dose adjustment of frovatriptan is not required in obese patients and therefore implies a lower need of tablets to be taken to relieve pain.

\section{Weekend migraine}

Migraine often occurs during weekends. However, evidence regarding efficacy of triptans in weekend migraine is limited. ${ }^{44}$ A retrospective analysis was performed in patients enrolled in the three head-to-head studies who had migraine attacks on weekends as well as workdays. ${ }^{23}$ The average number of migraine attacks was greater $(P<0.0001)$ during weekends (285 \pm 45 attacks) compared with workdays (256 \pm 37 attacks). The proportion pain-free at 2 hours did not significantly differ between weekend and workday attacks for either frovatriptan (26\% versus $27 \%$ ) or comparators $(34 \%$ versus $32 \%)$. However, the relapse rate within 48 hours for weekend compared with workday attacks was significantly lower with frovatriptan, but not with comparators (Table 2).

Therefore, among the different triptans, frovatriptan appears to offer the advantage of a lower risk of recurrence and more sustained antimigraine effect during weekend 
attacks. These results are an important addition to the literature given the paucity of data on this topic.

\section{Sex}

The importance of sex-specific medicine has been emerging worldwide over recent decades. In migraine, specific anatomical, hormonal, and behavioral components make the pathophysiology different between males and females. ${ }^{45}$ As migraine is considerably more common in females than in males, Franconi et $\mathrm{al}^{46}$ performed a retrospective analysis of the three head-to-head studies to address possible sex differences in response to antimigraine therapy. The proportion pain-free at 2 hours did not differ significantly between frovatriptan and comparators in either males or females, and pain relief was also similar between treatments for both sexes. However, the rate of relapse was significantly lower with frovatriptan than with the comparators in both males and female (Table 2). ${ }^{46}$

Although migraine tends to present in a more severe form in females than in males, frovatriptan was shown to be efficacious in both sexes, with a favorable sustained antimigraine effect compared with the comparators. ${ }^{46}$ These results represent an important addition to the currently sparse literature on the subject of sex in migraine.

\section{Safety}

Pooled analysis of the three randomized, controlled studies showed frovatriptan to be associated with significantly fewer adverse drug reactions, particularly cardiovascular symptoms. ${ }^{30}$ Tolerability of frovatriptan, used for immediate or repeated sustained use, also compares favorably against sumatriptan $^{47}$ and other acute therapies. ${ }^{11}$

\section{Cost-effectiveness of frovatriptan in the treatment of migraine}

Migraine has a large economic impact on society, with twothirds of the financial burden linked to indirect costs, such as effect on productivity at work. ${ }^{48,49}$ An economical advantage of frovatriptan among the oral triptans has been suggested, with model analysis based on the human capital approach showing frovatriptan to be significantly more cost-effective than rizatriptan in particular. ${ }^{49}$ This outcome is likely due to lower acquisition cost of frovatriptan, the need for fewer doses, and loss of fewer working hours. ${ }^{49}$

\section{Treatment of migraine in pediatric patients}

Although the present review focuses on frovatriptan treatment in the acute treatment of migraine in adults, the subject of migraine treatment in pediatric patients is a particularly challenging issue and also worthy of note here.

Management of pediatric migraine includes a comprehensive approach, using both pharmacologic as well as nonpharmacologic therapies. Children and adolescents often respond to over-the-counter medication, including NSAIDs or combination analgesics. ${ }^{50}$ Magnesium has been shown to increase the efficacy of ibuprofen and acetaminophen (paracetamol) in children. ${ }^{51}$ There is a paucity of data from randomized, controlled trials regarding triptan use in children and adolescents, and more studies are needed in this patient population. Intranasal sumatriptan and zolmitriptan are approved for use in adolescents in Europe; ${ }^{52}$ however, other triptans and formulations for children and adolescents are currently offlabel in Europe. Results of a double-blind, placebo-controlled study by Elkind et $\mathrm{al}^{53}$ showed the pharmacokinetic profile of frovatriptan in adolescents (12-17 years) to be similar to that seen in adults, suggesting that dosing adjustments would be unlikely to be required. The use of frovatriptan in adolescent patients may therefore be possible in the future, although further studies are needed.

Studies have shown beneficial effects of the herbal preparations ginkgolide B and Griffonia simplicifolia extract in children. ${ }^{54,55}$ Weight loss is associated with improvement in headache data in obese adolescent migraineurs. ${ }^{56,57}$

\section{Conclusion}

Triptans remain the preferred treatment option of the majority of patients and physicians for the acute treatment of adult migraine. ${ }^{8}$ A similar extent of initial migraine pain relief is afforded by frovatriptan and other second-generation triptan comparators rizatriptan, zolmitriptan, and almotriptan. Importantly, however, the longer duration of action of frovatriptan, which correlates with its pharmacokinetic profile, provides sustained efficacy and reduced relapse rate, compared with other triptans, offering a benefit to patients in the acute treatment of migraine. These results are consistent across a variety of patient profiles.

These benefits, together with potential advantages of cost-effectiveness versus other triptans, could drive selection of the most appropriate treatment for acute migraine attacks. In all cases, treatment should be tailored to the need of the individual patient.

\section{Acknowledgments}

Medical writing support was provided by Melanie More at Prime Medica Ltd (Knutsford, Cheshire, UK) during the preparation of this manuscript, funded by Menarini. The 
authors participated in the development and reviewing of the manuscript and the opinions and conclusions are those of the authors.

\section{Disclosure}

Both authors have occasionally served as scientific consultants for manufacturers of frovatriptan. The authors report no other conflicts of interest in this work.

\section{References}

1. Hazard E, Munakata J, Bigal ME, Rupnow MF, Lipton RB. The burden of migraine in the United States: current and emerging perspectives on disease management and economic analysis. Value Health. 2009; 12(1):55-64.

2. Headache Classification Committee of the International Headache Society (IHS). The International Classification of Headache Disorders, 3rd edition (beta version). Cephalalgia. 2013;33(9):629-808.

3. Martin VT, Lipton RB. Epidemiology and biology of menstrual migraine. Headache. 2008;48(Suppl 3):S124-S130.

4. Lipton RB, Stewart WF, Stone AM, Lainez MJ, Sawyer JP. Disability in Strategies of Care Group. Stratified care vs step care strategies for migraine: the Disability in Strategies of Care (DISC) Study: 4. A randomized trial. JAMA. 2000;284(20):2599-2605.

5. Sarchielli P, Granella F, Prudenzano MP, et al. Italian guidelines for primary headaches: 2012 revised version. J Headache Pain. 2012;13 (Suppl 2):S31-S70.

6. Johnston MM, Rapoport AM. Triptans for the management of migraine. Drugs. 2010;70(12):1505-1518.

7. Loder E. Triptan therapy in migraine. $N$ Engl J Med. 2010;363(1): 63-70.

8. Evers S, Lisotto C. An algorithm of migraine treatment. Eur Neurol Rev. 2013;8(2):149-152.

9. Balbisi EA. Frovatriptan: a review of pharmacology, pharmacokinetics and clinical potential in the treatment of menstrual migraine. Ther Clin Risk Manag. 2006;2(3):303-308.

10. Balbisi EA. Frovatriptan succinate, a 5-HT1B/1D receptor agonist for migraine. Int J Clin Pract. 2004;58(7):695-705.

11. Cady RK, Banks J, Jones BA, Campbell J. Postmarketing migraine survey of frovatriptan: effectiveness and tolerability vs previous triptans, NSAIDs or a combination. Curr Med Res Opin. 2009;25(11): 2711-2721.

12. Poolsup N, Leelasangaluk V, Jittangtrong J, Rithlamlert C, Ratanapantamanee N, Khanthong M. Efficacy and tolerability of frovatriptan in acute migraine treatment: systematic review of randomized controlled trials. J Clin Pharm Ther. 2005;30(6):521-532.

13. Savi L, Omboni S, Lisotto C, et al. A double-blind, randomized, multicenter, Italian study of frovatriptan versus rizatriptan for the acute treatment of migraine. J Headache Pain. 2011;12(2):219-226.

14. Tullo V, Allais G, Ferrari MD, et al. Frovatriptan versus zolmitriptan for the acute treatment of migraine: a double-blind, randomized, multicenter, Italian study. Neurol Sci. 2010;31(Suppl 1):S51-S54.

15. Bartolini M, Giamberardino MA, Lisotto C, et al. A double-blind, randomized, multicenter, Italian study of frovatriptan versus almotriptan for the acute treatment of migraine. $J$ Headache Pain. 2011;12(3):361-368.

16. Savi L, Omboni S, Lisotto C, et al. Efficacy of frovatriptan in the acute treatment of menstrually related migraine: analysis of a double-blind, randomized, cross-over, multicenter, Italian, comparative study versus rizatriptan. J Headache Pain. 2011;12(6):609-615.

17. Allais G, Tullo V, Benedetto C, Zava D, Omboni S, Bussone G. Efficacy of frovatriptan in the acute treatment of menstrually related migraine: analysis of a double-blind, randomized, multicenter, Italian, comparative study versus zolmitriptan. Neurol Sci. 2011;32(Suppl 1) S99-S104.
18. Bartolini M, Giamberardino MA, Lisotto C, et al. Frovatriptan versus almotriptan for acute treatment of menstrual migraine: analysis of a double-blind, randomized, cross-over, multicenter, Italian, comparative study. J Headache Pain. 2012;13(5):401-406.

19. Allais G, Tullo V, Omboni S, et al. Efficacy of frovatriptan versus other triptans in the acute treatment of menstrual migraine: pooled analysis of three double-blind, randomized, crossover, multicenter studies. Neurol Sci. 2012;33(Suppl 1):S65-S69.

20. Allais G, Tullo V, Omboni S, et al. Frovatriptan vs other triptans for the acute treatment of oral contraceptive-induced menstrual migraine: pooled analysis of three double-blind, randomized, crossover, multicenter studies. Neurol Sci. 2013;34(Suppl 1):S83-S86.

21. Tullo V, Bussone G, Omboni S, et al. Efficacy of frovatriptan and other triptans in the treatment of acute migraine of hypertensive and normotensive subjects: a review of randomized studies. Neurol Sci. 2013;34(Suppl 1):S87-S91.

22. Saracco MG, Allais G, Tullo V, et al. Efficacy of frovatriptan and other triptans in the treatment of acute migraine of normal weight and obese subjects: a review of randomized studies. Neurol Sci. 2014;35 (Suppl 1):115-119.

23. Lisotto C, Savi L, Pinessi L, Guidotti M, Omboni S, Zanchin G. Efficacy of frovatriptan vs other triptans in weekend migraine: Pooled analysis of three double-blind, randomized, crossover, multicenter studies. Brain Disord Ther. 2014;3:128.

24. Evers S, Savi L, Omboni S, Lisotto C, Zanchin G, Pinessi L. Efficacy of frovatriptan as compared to other triptans in migraine with aura. J Headache Pain. 2015;16:514.

25. Tullo V, Allais G, Curone M, et al. Frovatriptan versus zolmitriptan for the acute treatment of migraine with aura: a double-blind, randomized, multicenter, Italian study. Neurol Sci. 2012;33(Suppl 1):S61-S64.

26. Allais G, Tullo V, Cortelli P, et al. Efficacy of early vs late use of frovatriptan combined with dexketoprofen vs frovatriptan alone in the acute treatment of migraine attacks with or without aura. Neurol Sci. 2014;35(Suppl 1):107-113.

27. Allais G, Bussone G, Tullo V, et al. Early $(</=1-\mathrm{h})$ vs late $(>1-\mathrm{h})$ administration of frovatriptan plus dexketoprofen combination vs frovatriptan monotherapy in the acute treatment of migraine attacks with or without aura: a post hoc analysis of a double-blind, randomized, parallel group study. Neurol Sci. 2015;36(Suppl 1):161-167.

28. Tullo V, Valguarnera F, Barbanti P, et al. Comparison of frovatriptan plus dexketoprofen $(25 \mathrm{mg}$ or $37.5 \mathrm{mg}$ ) with frovatriptan alone in the treatment of migraine attacks with or without aura: a randomized study. Cephalalgia. 2014;34(6):434-445.

29. Headache Classification Subcommittee of the International Headache Society. The International Classification of Headache Disorders: 2nd edition. Cephalalgia. 2004;24(Suppl 1):9-160.

30. Cortelli P, Allais G, Tullo V, et al. Frovatriptan versus other triptans in the acute treatment of migraine: pooled analysis of three double-blind, randomized, cross-over, multicenter, Italian studies. Neurol Sci. 2011;32 (Suppl 1):S95-S98.

31. Allais G, Benedetto C. A review of the use of frovatriptan in the treatment of menstrually related migraine. Ther Adv Neurol Disord. 2013; 6(2):55-67.

32. Allais G, Castagnoli Gabellari I, De Lorenzo C, Mana O, Benedetto C. Menstrual migraine: clinical and therapeutical aspects. Expert Rev Neurother. 2007;7(9):1105-1120.

33. Recober A, Geweke LO. Menstrual migraine. Curr Neurol Neurosci Rep. 2005;5(2):93-98.

34. MacGregor EA. Prevention and treatment of menstrual migraine. Drugs. 2010;70(14):1799-1818.

35. Migard SPC 2014. Migard SPC 2014. Available from: https://www. medicines.org.uk/emc/medicine/15216. Accessed November 1, 2015.

36. Silberstein SD, Holland S, Freitag F, Dodick DW, Argoff C, Ashman E. Evidence-based guideline update: pharmacologic treatment for episodic migraine prevention in adults: report of the Quality Standards Subcommittee of the American Academy of Neurology and the American Headache Society. Neurology. 2012;78(17):1337-1345. 
37. Mainardi F, Maggioni F, Pezzola D, Zava D, Zanchin G. Dexketoprofen trometamol in the acute treatment of migraine attack: a phase II, randomized, double-blind, crossover, placebo-controlled, dose optimization study. J Pain. 2014;15(4):388-394.

38. Allais G, De Lorenzo C, Airola G, Peano S, Benedetto C. [Dexketoprofen trometamol in the treatment of acute migraine attack]. Minerva Med. 2000;91(7-8):153-159.

39. D'Amico D, Moschiano F, Bussone G. Early treatment of migraine attacks with triptans: a strategy to enhance outcomes and patient satisfaction? Expert Rev Neurother. 2006;6(7):1087-1097.

40. Haut S. Differentiating migraine from epilepsy. Adv Stud Med. 2005; 5(6E):S658-S665.

41. Barbanti P, Aurilia C, Egeo G, Fofi L. Hypertension as a risk factor for migraine chronification. Neurol Sci. 2010;31(Suppl 1):S41-S43.

42. Bigal ME, Lipton RB, Holland PR, Goadsby PJ. Obesity, migraine, and chronic migraine: possible mechanisms of interaction. Neurology. 2007;68(21):1851-1861.

43. Peres MF, Lerario DD, Garrido AB, Zukerman E. Primary headaches in obese patients. Arq Neuropsiquiatr. 2005;63(4):931-933.

44. Guidotti M, Barrila C, Leva S, De PC, Omboni S. Symptomatic or prophylactic treatment of weekend migraine: an open-label, nonrandomized, comparison study of frovatriptan versus naproxen sodium versus no therapy. Neuropsychiatr Dis Treat. 2013;9:81-85.

45. Peterlin BL, Gupta S, Ward TN, Macgregor A. Sex matters: evaluating sex and gender in migraine and headache research. Headache. 2011; 51(6):839-842.

46. Franconi F, Finocchi C, Allais G, et al. Gender and triptan efficacy: a pooled analysis of three double-blind, randomized, crossover, multicenter, Italian studies comparing frovatriptan vs other triptans. Neurol Sci. 2014;35(Suppl 1):99-105.

47. Geraud G, Spierings EL, Keywood C. Tolerability and safety of frovatriptan with short- and long-term use for treatment of migraine and in comparison with sumatriptan. Headache. 2002;42(Suppl 2): S93-S99.
48. Edmeads J, Mackell JA. The economic impact of migraine: an analysis of direct and indirect costs. Headache. 2002;42(6):501-509.

49. Lisotto C, Guidotti M, Zava D, Savi L. Frovatriptan and rizatriptan economic EVAluation: the FREEVA study. J Headache Pain. 2013; 14:96.

50. Sonal Sekhar M, Sasidharan S, Joseph S, Kumar A. Migraine management: How do the adult and paediatric migraines differ? Saudi Pharm J. 2012;20(1):1-7.

51. Gallelli L, Avenoso T, Falcone D, et al. Effects of acetaminophen and ibuprofen in children with migraine receiving preventive treatment with magnesium. Headache. 2014;54(2):313-324.

52. Tepper SJ. Clinical implications for breath-powered powder sumatriptan intranasal treatment. Headache. 2013;53(8):1341-1349.

53. Elkind AH, Wade A, Ishkanian G. Pharmacokinetics of frovatriptan in adolescent migraineurs. J Clin Pharmacol. 2004;44(10):1158-1165.

54. Esposito M, Carotenuto M. Ginkgolide B complex efficacy for brief prophylaxis of migraine in school-aged children: an open-label study. Neurol Sci. 2011;32(1):79-81.

55. Esposito M, Ruberto M, Pascotto A, Carotenuto M. Nutraceutical preparations in childhood migraine prophylaxis: effects on headache outcomes including disability and behaviour. Neurol Sci. 2012;33(6): 1365-1368.

56. Verrotti A, Agostinelli S, D’Egidio C, et al. Impact of a weight loss program on migraine in obese adolescents. Eur J Neurol. 2013;20(2): 394-397.

57. Verrotti A, Carotenuto M, Altieri L, et al. Migraine and obesity: metabolic parameters and response to a weight loss programme. Pediatr Obes. 2015;10(3):220-225.

58. Comer MB. Pharmacology of the selective 5-HT(1B/1D) agonist frovatriptan. Headache. 2002;42(Suppl 2):S47-S53.
Drug Design, Development and Therapy

\section{Publish your work in this journal}

Drug Design, Development and Therapy is an international, peerreviewed open-access journal that spans the spectrum of drug design and development through to clinical applications. Clinical outcomes, patient safety, and programs for the development and effective, safe, and sustained use of medicines are the features of the journal, which

\section{Dovepress}

has also been accepted for indexing on PubMed Central. The manuscript management system is completely online and includes a very quick and fair peer-review system, which is all easy to use. Visit http://www.dovepress.com/testimonials.php to read real quotes from published authors. 